\section{Kidney \\ Blood Pressure Research}

\title{
Associations of Smoking with Alterations in Renal Hemodynamics May Depend on Sex- Investigations in Potential Kidney Donors
}

\author{
Hana Guberina ${ }^{a} \quad$ Marcus Baumann ${ }^{b} \quad$ Heike Bruck $^{a}$ Thorsten Feldkamp ${ }^{a}$ \\ Jens Nürnberger ${ }^{a, c} \quad$ Andreas Kribben ${ }^{a}$ Thomas Philipp ${ }^{a} \quad$ Oliver Witzke ${ }^{a}$ \\ Georgios Sotiropoulos ${ }^{d}$ Anna Mitchella
}

aDepartment of Nephrology, Essen University Hospital, Essen; ${ }^{b}$ Department of Nephrology, Technical University of Munich, Munich; 'Department of Nephrology and Dialysis, HELIOS Kliniken Schwerin, Schwerin; dDepartment of General, Visceral and Transplantation Surgery, Essen University Hospital, Essen, Germany

\section{Key Words}

Smoking • Renal hemodynamics • Effective renal plasma flow • Glomerular hydrostatic pressure

\begin{abstract}
Background/Aims: Cigarette smoking is a risk factor for renal damage, but little is known about subclinical effects of smoking on renal hemodynamics and parameters of renal function in humans. We examined the associations of smoking with systemic and renal hemodynamics and renal function parameters in healthy individuals. Methods: Data from 196 potential living kidney donors were analysed retrospectively. Mean arterial blood pressure (MAP), effective renal plasma flow (ERPF) and creatinine clearance had been measured. We additionally calculated parameters of renal hemodynamics. Data were analyzed for the effects of smoking and sex dependent on age and MAP. Results: Systemic and renal hemodynamic parameters did not differ between smokers and non-smokers. In non-smokers of both sexes MAP was negatively correlated with ERPF, and higher MAP was associated with increased renal vascular resistance and with afferent arteriolar resistance, with glomerular pressure $\left(P_{G}\right)$ remaining constant. However, in male, but not in female smokers, ERPF and $P_{G}$ increased with MAP. A correlation of age with a steeper decline in ERPF in male smokers was lost in multiple regression analysis. Conclusions: As compared to women, smoking men may exhibit an increased glomerular hydrostatic pressure, which is a known promoter of kidney damage.
\end{abstract}




\section{Kidney \\ Blood Pressure Research}

\section{Introduction}

Cigarette smoking is one of the major self-inflicted cardiovascular risk factors increasing the risk of premature morbidity and mortality [1-3]. Previous studies have demonstrated that adverse cardiovascular effects of smoking go hand in hand with renal function impairment, independent of underlying renal disease [4-6], and accelerate deterioration of renal function to end-stage renal failure [7,8]. Mechanisms underlying smoking-induced renal impairment are not completely understood. However, endothelial injury promoted by smoking as well as atherosclerotic changes, have been recognized as two major factors $[9,10]$. Increased microalbuminuria- and proteinuria-rates representing significant and early indicators of renal damage have repeatedly been related to chronic cigarette smoking [11-13]. It has also been shown that cigarette smoking has acute as well as chronic effects on systemic and renal hemodynamics. Long-term smoking has been associated with elevated blood pressure and reduced renal plasma flow [14-18]. Acute nicotine application induces an increase in arterial blood pressure as well as an alteration in renal function and hemodynamics [19, 20]. These findings indicate alterations of renovascular responses to increases in blood pressure in chronic smokers. There is little data regarding the effects of chronic cigarette smoking on renal hemodynamics and function in otherwise healthy individuals, but the existing evidence supports the concept of a detrimental influence of cigarette smoking on kidney function [21]. Advancing age and sex are well known factors in renal function decline and progression of renal disease, which need to be considered when effects of smoking are investigated [22,23].

Therefore, to clarify the role of chronic smoking on renal function in a healthy, normotensive population and to determine its effects on renal hemodynamic parameters, we assessed the interaction between systemic blood pressure and renal hemodynamics as well as functional parameters in smokers and non-smokers dependent on age and sex.

\section{Materials and Methods}

\section{Study population}

Medical records of 196 individuals ( $\mathrm{n}=124$ women, 72 men) aged 27 to 70 years (mean age \pm SD 46.7 \pm 10.9 years) included in the living kidney donor program at Essen University Hospital, Germany, between 1998 and 2010, were reviewed retrospectively. Prior to kidney donation all potential donors underwent extensive diagnostic procedures to exclude relevant renal and extra-renal diseases. Individuals with renal insufficiency or a history of hypertension, cardiovascular disease, diabetes mellitus, metabolic syndrome or malignancies were excluded from the living kidney donor program [24]. Smoking status and habits were quantified based on self-report. Of the 196 individuals $37 \%$ ( $\mathrm{n}=43$ women, 29 men) were chronic smokers, which is in agreement with the smoking prevalence seen in Western Europe [25]. For the purpose of this study chronic smoking was defined as a habit of long term regular smoking of at least one cigarette on a daily basis [26]. Demographic characteristics as well as clinical and laboratory data of the selected subjects are shown in table 1 . If multiple test results were present, those closest to kidney donation were analysed.

\section{Blood pressure and laboratory measurements}

Ambulatory 24-hour blood pressure (BP) registrations were performed with an oscillometric device (Mobil-O-Graph® Holter-RR 24 h ABP-Monitor, I.E.M. GmbH, Stolberg Germany). Venous blood samples were collected for analysis of routine blood parameters.

\section{Renal hemodynamic parameters and renal function}

Effective renal plasma flow (ERPF) was assessed via ${ }^{99 \mathrm{~m}} \mathrm{Tc}-$ mercaptoacetyltriglycine- $\left({ }^{99 \mathrm{~m}} \mathrm{Tc}-\mathrm{MAG}_{3}\right.$ ) and ${ }^{131} \mathrm{I}$-hippuran- $\left({ }^{131} \mathrm{I}-\mathrm{OIH}\right)$ clearance-measurements. ${ }^{99 \mathrm{~m}} \mathrm{Tc}_{\mathrm{C}} \mathrm{MAG}_{3}$ - and ${ }^{131} \mathrm{I}-\mathrm{OIH}$ clearance values are known to

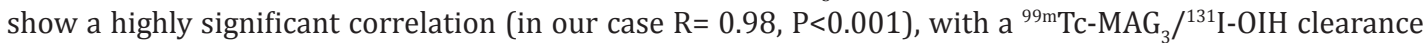
ratio of approximately 0.60 [27]. We observed similar results when correlating ERPF estimated from ${ }^{99 \mathrm{~m}} \mathrm{Tc}$ $\mathrm{MAG}_{3}$ - and by ${ }^{131} \mathrm{I}$-OIH-clearance, respectively, and therefore decided only to present correlation analyses with ERPF estimated by ${ }^{99 \mathrm{~m}} \mathrm{Tc}-\mathrm{MAG}_{3}$-clearance. 


\section{Kidney Blood Pressure Research}

Kidney Blood Press Res 2013;37:611-621

DOI: 10.1159/000355741

Published onlıne: December 15, 2013

(C) 2013 S. Karger AG, Base

Guberina et al.: Smoking-Induced Changes of Renal Hemodynamics

Table 1. Clinical characteristics and surrogate parameters for cardiovascular risk (group mean averages \pm SD) in total and separately for men and women. Abbr.: BMI = Body Mass Index, MAP = Mean Arterial Pressure, BP = Blood Pressure, HDL = High Density Lipoprotein

\begin{tabular}{lcccc}
\hline Parameter & Total & Women & Men & t-Test \\
\cline { 2 - 5 } & $\mathrm{n}=196$ & $\mathrm{n}=124$ & $\mathrm{n}=72$ & $\mathrm{P}$ \\
& & $(63 \%)$ & $(37 \%)$ & \\
\hline Age (years) & $46 \pm 10$ & $47 \pm 10$ & $42 \pm 10$ & 0.001 \\
BMI (kg/m ${ }^{2}$ ) & $25.5 \pm 4$ & $25.3 \pm 5$ & $25.9 \pm 3$ & $\mathrm{~ns}$ \\
MAP (mmHg) & $85 \pm 6$ & $84 \pm 6$ & $87 \pm 5$ & 0.007 \\
Systolic BP (mmHg) & $115 \pm 8$ & $114 \pm 8$ & $117 \pm 7$ & 0.03 \\
Diastolic BP (mmHg) & $71 \pm 6$ & $70 \pm 6$ & $72 \pm 6$ & 0.03 \\
Heart rate (bpm) & $74 \pm 11$ & $73 \pm 10$ & $74 \pm 13$ & $\mathrm{~ns}$ \\
Plasma total cholesterol (mg/dL) & $217 \pm 40$ & $217 \pm 39$ & $218 \pm 41$ & $\mathrm{~ns}$ \\
Plasma HDL cholesterol (mg/dL) & $59 \pm 8$ & $63 \pm 16$ & $50 \pm 14$ & $<0.001$ \\
Fasting glucose (mg/dL) & $90 \pm 8$ & $89 \pm 7$ & $90 \pm 9$ & $\mathrm{~ns}$ \\
\hline
\end{tabular}

Glomerular filtration rate (GFR) was calculated using the endogenous creatinine-clearance. This was determined from the 2 x2-hour urinary creatinine excretion rate divided by plasma creatinine concentration. Both GFR and ERPF values were corrected for standard body surface area $\left(1.73 \mathrm{~m}^{2}\right)$. The filtration fraction (FF) was calculated as the ratio of GFR and ERPF and is expressed in percent [28]. Renal vascular resistance (RVR) was calculated as the ratio of mean arterial blood pressure (MAP) to ERPF [29]. Intrarenal hemodynamics, such as glomerular hydrostatic pressure $\left(P_{G}\right)$, afferent $\left(R_{A}\right)$ and efferent $\left(R_{E}\right)$ arteriolar resistance, cannot be measured directly in humans. They were therefore calculated according to the formulae established by Gomez et al. [30, 31], (Abbreviations see page 619):

$$
\begin{aligned}
& P_{G}=\frac{G F R}{K_{F G}}+H_{T}+5 \times\left(\frac{T P}{F F} \times \log e \frac{1}{1-F F}-2\right) \\
& R_{A}=\frac{M A P-P_{G}}{E R B F} \times 1328 \quad(1328=\text { conversion factor }) \\
& R_{E}=\frac{G F R}{K_{F G} \times(E R B F-G F R)} \times 132 \varepsilon
\end{aligned}
$$

Statistical analysis

Analyses were performed using SPSS Software (release 17.0; SPSS Inc., Chicago, IL, USA). Quantitative data are expressed as mean \pm standard deviation and as n (\%) for categorical variables. Data were analysed for the influence of chronic smoking habits in the total study population as well as in men and women, respectively. T-tests were used to compare the differences of variables between population groups. In smokers and non-smokers overall and subdivided according to sex, linear univariate regression analyses were performed to test correlations between renal function and renal hemodynamic parameters with age and MAP. A multiple linear regression test was then used to evaluate the relationship between ERPF and MAP, after adjusting for age and sex in non-smokers and smokers. P-values of $\leq 0.05$ were considered statistically significant.

\section{Results}

\section{Patients' cohorts}

Screening data from 196 potential living kidney donors (total cohort $\mathrm{n}=196$, mean age $46 \pm 10$ years; women $n=124,47 \pm 10$ years; men $n=72,42 \pm 10$ years) were included in the analyses.

\section{Demographic characteristics of the total cohort and according to sex}

Demographic data as well as surrogate parameters for cardiovascular risk of the total cohort and separately for men and women are summarized in table 1: Men were significantly younger than women and had higher blood pressure and lower HDL cholesterol. There was no significant difference in body mass index, heart rate, total cholesterol and fasting glucose between the sexes. Smoking prevalence and number of pack years were similar in men and women. 72 of 196 individuals were chronic smokers (37\% of the total cohort; 35\% of men, and $38 \%$ of women). 


\section{Kidney \\ Blood Pressure Research}

\section{Kidney Blood Press Res 2013;37:611-621}

DOI: 10.1159/000355741

Published onlıne: December 15, 2013

C 2013 S. Karger AG, Basel

www.karger.com/kbr
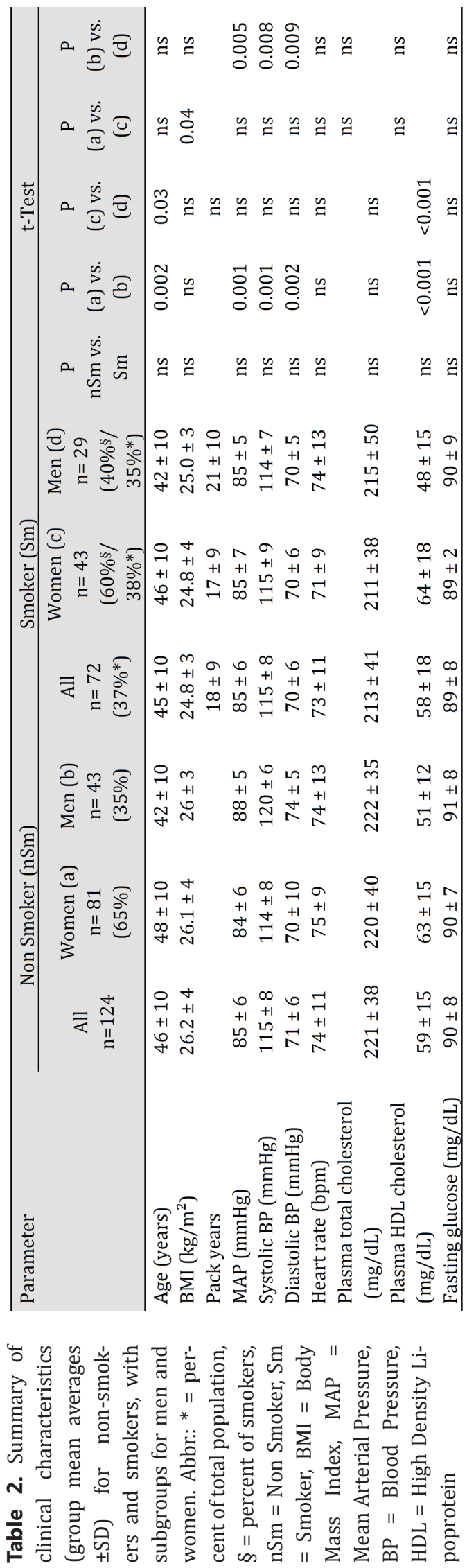

Demographic characteristics according to smoking status and sex

Table 2 shows cardiovascular and metabolic variables for the subgroups of non-smokers and smokers in total and separately for men and women. Taken as a whole, smokers did not differ from nonsmokers with regard to age, body mass index, systemic hemodynamics, lipid status and fasting glucose levels. Both non-smoking and smoking men were younger than women in the respective subgroups. In non-smokers blood pressure was higher in men. There was no sex-dependent difference in blood pressure values in smokers.

Renal hemodynamics of the total cohort and according to sex

Table 3 presents renal hemodynamics and renal function parameters for the total cohort and separately for men and women. Men had higher values for plasma creatinine, creatinine clearance, filtration fraction, ${ }^{99 \mathrm{~m}} \mathrm{Tc}-$ $\mathrm{MAG}_{3}$ - and ${ }^{131} \mathrm{I}$-OIH- clearance.

\section{Renal hemodynamics according to} smoking status and sex

Table 4summarizes renal hemodynamics and renal function parameters for nonsmokers and smokers in total and separately for men and women. Overall, renal hemodynamics and parameters of kidney function were similar in smokers and nonsmokers. Irrespective of smoking status, plasma creatinine, creatinine clearance and filtration fraction were higher in men. ${ }^{99 \mathrm{~m}} \mathrm{Tc}$ $\mathrm{MAG}_{3}$ - and ${ }^{131} \mathrm{I}-\mathrm{OIH}$ - clearances were similar in non-smokers of both sexes but were higher in smoking men.

\section{Correlation analyses}

Correlations of ERPF and GFR with age. In the total cohort $(\mathrm{n}=196), \mathrm{GFR}$ and ERPF significantly decreased with age, with no significant difference between the sexes (GFR: $\mathrm{R}=-0.32, \mathrm{P}<0.001$, ERPF: $\mathrm{R}=-0.37$, $\mathrm{P}<0.001)$. Overall smoking status did not influence the negative correlation of GFR and ERPF with age.

The age-related decline in ERPF was steeper in male smokers than in nonsmokers but did not differ in non-smoking and in smoking women (non-smoking men $\mathrm{R}=-0.35, \mathrm{P}<0.01$; smoking men $\mathrm{R}=-0.53$, 


\section{Kidney Blood Pressure Research}

Table 3. Renal function parameters in total and separately for men and women. Abbr: MAG3 = Mercaptoacetyltriglycine, $\mathrm{I}-\mathrm{OIH}=\mathrm{I}-\mathrm{Hip}-$ puran, $\mathrm{RVR}=$ Renovascular Resistance

Parameter
Creatinine clearance $\left(\mathrm{ml} / \mathrm{min} / 1.73 \mathrm{~m}^{2}\right)$
MAG3 Clearance $\left(\mathrm{ml} / \mathrm{min} / 1.73 \mathrm{~m}^{2}\right)$
I-OIH Clearance $\left(\mathrm{ml} / \mathrm{min} / 1.73 \mathrm{~m}^{2}\right)$
Filtration fraction $(\%)$
RVR (mmHg*min/L)
Plasma creatinine (mmol/L)
Table 4. Renal function parameters for
non-smokers and smokers, with sub-
groups for men and women. Abbr: *
percent of total population, $\S=$ percent of
smokers, nSm = Non Smoker, Sm = Smok-
er, MAG3 = Mercaptoacetyltriglycine,
I-OIH = I-Hippuran, RVR = Renovascular
Resistance

$\mathrm{P}<0.001$; non-smoking men vs. smoking men $\mathrm{P}$ $=0.05$; non-smoking women $\mathrm{R}=-0.28, \mathrm{P}<0.01$, smoking women $\mathrm{R}=-0.34, \mathrm{P}<0.05)$. However, this correlation was lost in multiple regression analysis (see below).

Correlations of ERPF and GFR with MAP. Figure 1 shows the relationship between ERPF and MAP for non-smokers (figure 1A) and smokers (figure 1B) along with the corresponding subgroups (women and men). In non-smokers there was a significant negative correlation between ERPF and MAP $(\mathrm{R}=-0.34, \mathrm{P}<0.001)$ in women as well as in men $(\mathrm{R}=-0.304, \mathrm{P}<0.01 ; \mathrm{R}=-0.379, \mathrm{P}<0.05$, respectively), which remained significant after adjusting for age and sex $(\mathrm{R}=-0.38 ; \mathrm{P}<0.001)$. Smokers overall showed no significant association between MAP and ERPF ( $\mathrm{R}=0.17 ; \mathrm{P}=\mathrm{ns})$.

However, in smokers sex-dependent differences emerged: In men but not in women, ERPF increased in parallel with MAP (male smokers: $\mathrm{R}=0.44 ; \mathrm{P}<0.05$, female smokers: $\mathrm{R}=$ $0.05 ; \mathrm{P}=\mathrm{ns}$ ). In a multiple regression analysis ERPF remained significantly associated with sex, smoking status and MAP $(\mathrm{R}=0.868 ; \mathrm{P}=0.01$; sex $\mathrm{P}=0.015$; smoking $\mathrm{P}=0.006$; $\mathrm{MAP} \mathrm{P}=0.001$ ) but not with age. On correlating GFR and MAP, GFR remained constant independent of MAP in the overall population, and there were no significant differences between the subgroups of chronic smokers and non-smokers or between sexes (data not shown).

Influence of MAP on intrarenal hemodynamics. Therelationshipbetweenintrarenalhemodynamics and MAP is shown in figure 2. In non-smokers, lower values for ERPF in the presence of higher MAP were associated with increased RVR (R=

$\begin{array}{cccc}\text { Total } & \text { Women } & \text { Men } & \text { t-Test } \\ \mathrm{n}=196 & \begin{array}{c}\mathrm{n}=124 \\ (63 \%)\end{array} & \begin{array}{c}\mathrm{n}=72 \\ (37 \%)\end{array} & \mathrm{P} \\ & 92 \pm 16 & 104 \pm 17 & <0.001 \\ 97 \pm 17 & 254 \pm 32 & 262 \pm 34 & \mathrm{~ns} \\ 257 \pm 33 & 426 \pm 55 & 439 \pm 52 & \mathrm{~ns} \\ 431 \pm 54 & 22 \pm 4 & 24 \pm 4 & 0.02 \\ 23 \pm 4 & 0.19 \pm 0.03 & 0.2 \pm 0.03 & \mathrm{~ns} \\ 0.2 \pm 0.03 & 0.190 .1 & 0.001 \\ 0.94 \pm 0.2 & 0.88 \pm 0.1 & 1.1 \pm 0.1 & \end{array}$

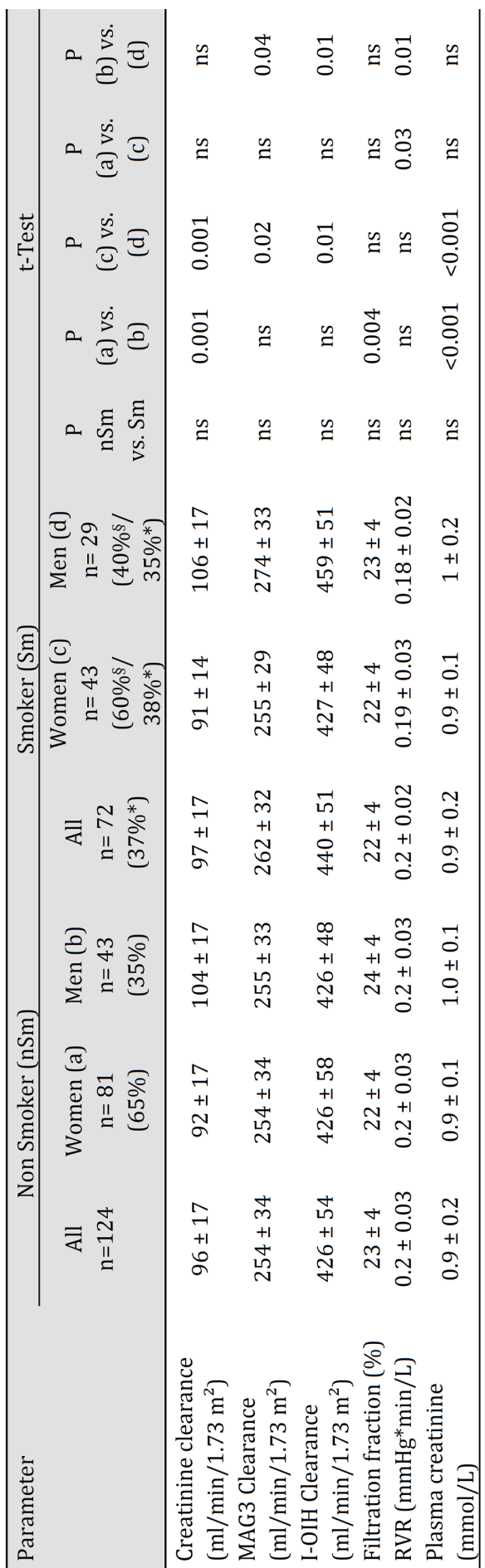




\section{Kidney Bloód Pressure Research}

Fig. 1. Variations of effective renal plasma flow (ERPF) with mean systemic arterial pressure (MAP) for non-smokers (A) and chronic smokers (B) and within these groups for women $(O)$ and men ( $\square$ ).

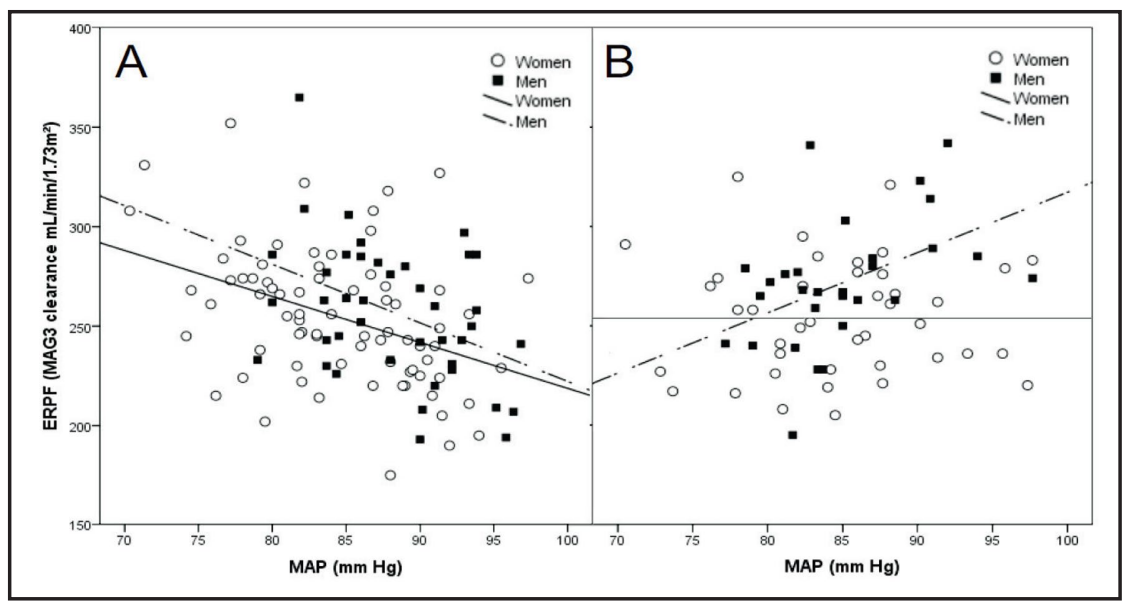

0.69; $\mathrm{P}<0.001$; figure 2A). The increase in RVR did not differ between non-smoking men and women (women $\mathrm{R}=0.70 ; \mathrm{P}<0.001$, men $\mathrm{R}=0.68 ; \mathrm{P}<0.001$ ). In smokers, higher MAP was associated with higher RVR in women but not in men (women $\mathrm{R}=0.56 ; \mathrm{P}<0.001$, men $\mathrm{R}=$ 0.20 ; $\mathrm{P}=\mathrm{ns}$, figure $2 \mathrm{~B}$ ).

As illustrated in figure 2 , in non-smokers $\mathrm{R}_{\mathrm{A}}$ was significantly and positively correlated with MAP with no difference between the sexes (men $\mathrm{R}=0.75 ; \mathrm{P}<0.001$, women $\mathrm{R}=0.78$; $\mathrm{P}<$ 0.001). $R_{E}$ showed a tendency to be elevated with higher MAP, but this was not statistically significant (men $\mathrm{R}=0.18$; $\mathrm{P}=\mathrm{ns}$, women $\mathrm{R}=0.12$; $\mathrm{P}=\mathrm{ns}$; figure $2 \mathrm{G}$ ). Glomerular pressure $\mathrm{P}_{\mathrm{G}}$ remained constant in non-smokers and there was no significant correlation with MAP (nonsmoking men and women $\mathrm{R}=0.14, \mathrm{P}=\mathrm{ns}$; figure $2 \mathrm{E}$ ).

Again within the subgroup of chronic smokers differences between the sexes were revealed: In smoking women results for intrarenal hemodynamics resembled those of nonsmoking individuals $\left(\mathrm{R}_{A} \mathrm{R}=0.81, \mathrm{P}<0.001 ; \mathrm{R}_{\mathrm{E}} \mathrm{R}=0.10, \mathrm{P}=\mathrm{ns} ; \mathrm{P}_{\mathrm{G}} \mathrm{R}=0.14, \mathrm{P}=\mathrm{ns} ; \mathrm{P}=\right.$ ns vs. nonsmoking women; figure $2 \mathrm{D} / \mathrm{F} / \mathrm{H})$. However, in male smokers, $\mathrm{R}_{\mathrm{A}}$ increased less with higher MAP than in non-smokers (male smokers: $\mathrm{R}=0.42 ; \mathrm{P}<0.05 ; \mathrm{P}<0.05$ for the correlation and vs. male non-smokers); in smoking men $\mathrm{R}_{\mathrm{A}}$ also increased less with higher MAP than in female smokers $(\mathrm{P}<0.05)$. In male smokers, glomerular pressure $P_{G}$ was significantly positively correlated with MAP $(\mathrm{R}=0.48 ; \mathrm{P}<0.01$; figure $2 \mathrm{~F})$, while there was no significant association between MAP and $\mathrm{R}_{\mathrm{E}}$ in smoking men ( $\mathrm{R}=0.2 ; \mathrm{P}=\mathrm{ns}$; figure $2 \mathrm{H}$ ).

Correlations of FF with age or MAP. No correlation was found for FF with age or MAP, either in the whole population or in any subgroup (data not shown).

\section{Discussion}

Our study is the first to show in humans in vivo that renal autoregulation in smokers may vary dependent on sex. Significant sex-specific differences between smokers and nonsmokers emerged, when renal hemodynamics and functional parameters were related to mean arterial pressure. Our data suggest that men may be more susceptible than women to smoking-induced alterations of intrarenal hemodynamics. Analyses were performed in healthy individuals from a living kidney donor program. As far as our cohort in total is concerned, subject characteristics reflect those from other studies and epidemiological data with regard to several core parameters: More women than men were evaluated as living kidney donors [32]. Blood pressure was higher in men, as were creatinine values, GFR and filtration fraction [33-35].

When relating ERPF to mean arterial pressure we found an increasing influence of blood pressure in smoking men but not in smoking women: In female chronic smokers ERPF remained constant independent of systemic blood pressure. At the same time afferent and efferent arteriolar resistance responses in smoking women were similar to those of non- 

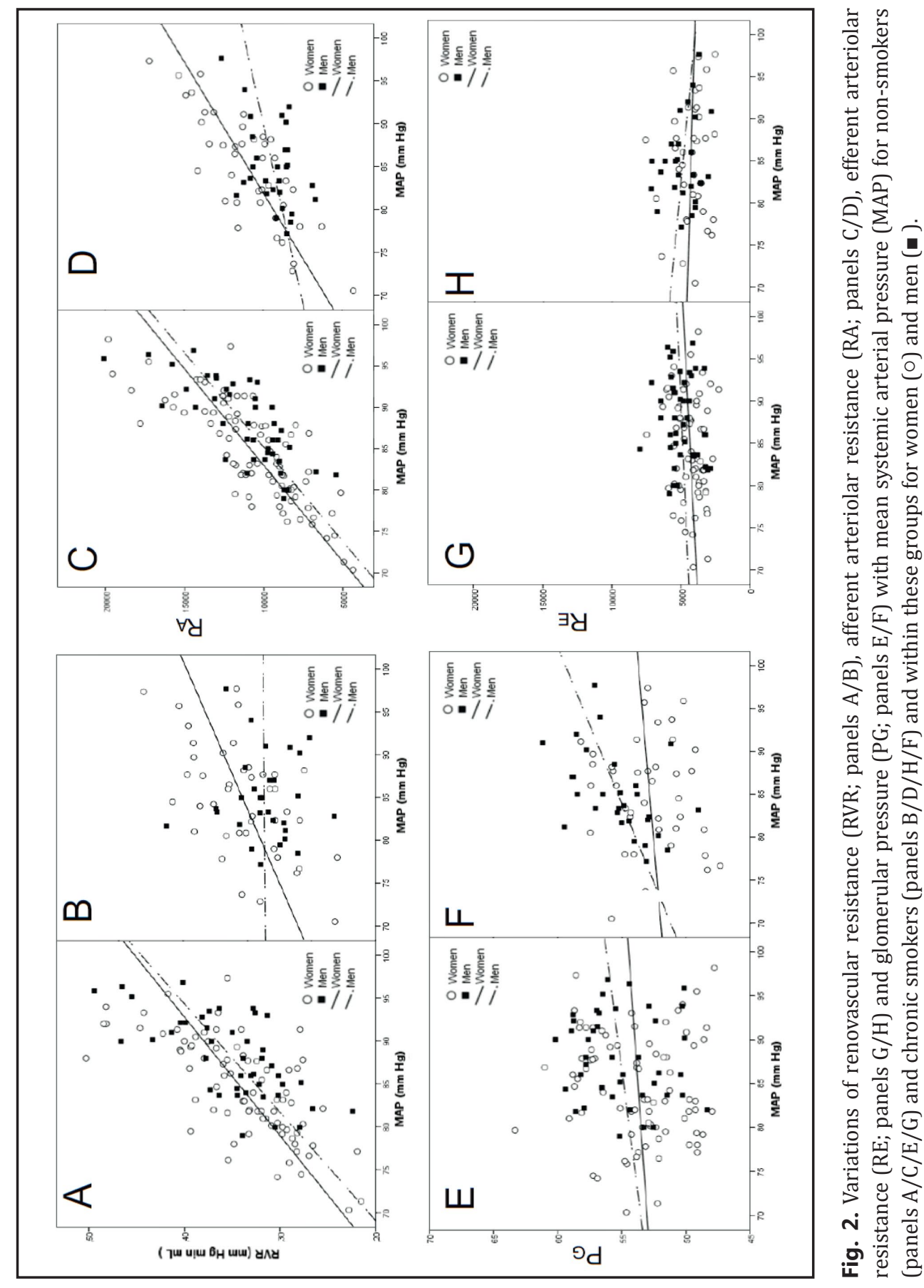

smokers, and glomerular hydrostatic pressure remained unaffected by blood pressure changes. However, in male chronic smokers ERPF increased in parallel with blood pressure. This can likely be attributed to a lesser MAP-associated increase in afferent arteriolar resistance in this group.

Earlier studies in healthy humans have shown that a rise in blood pressure (even within the normal range) causes vasoconstriction of renal afferent arterioles and thereby reduces renal plasma flow, thus protecting the glomerulus against hyperfiltration [16-18, 36].

In contrast our results indicate that in men chronic cigarette smoking may increase glomerular hydrostatic pressure via vasodilatory mechanisms in the afferent arteriole. This is in line with results of Halmai et al., who showed in healthy male chronic smokers as well as 


\section{Kidney Blood Pressure Research}

\begin{tabular}{l|l}
\hline DOI: $10.1159 / 000355741$ & C 2013 S. Karger AG, Basel \\
\hline
\end{tabular}

Published online: December 15, 2013

www.karger.com/kbr

Guberina et al.: Smoking-Induced Changes of Renal Hemodynamics

in animal studies that cigarette smoking affects renal autoregulation by inducing relaxation and in parallel a decrease in the resistance index of the renal arteries [37]. This seems counterintuitive since a wealth of data has shown that chronic cigarette smoking changes and ultimately damages endothelial function [38-40]. A comprehensive review of endothelial dysfunction associated with smoking and nicotine in various regional vascular beds has recently been published by Toda \& Toda [40]. Nicotine but also other toxic substances found in cigarette smoke promote oxidative stress, impaired nitric oxide bioavailability, increased endothelin production and vascular inflammation, which lead to endothelial and vascular smooth muscle dysfunction and ultimately to hypertension [40, 41]. The biochemical mechanisms of smoking-induced cellular damage are based on the over-production of vasoconstrictor and nitric-oxide-scavenging reactive oxygen species through decreased tetrahydrobiopterin (BH4)-concentrations and NADPH diaphorase activity [40]. These, in turn, can contribute to mitochondrial ATP-depletion and cellular damage [42].

Our data, however, suggest an exaggerated effect of endogenous vasodilators in the renal vasculature of male chronic smokers. The underlying mechanisms in this setting remain to be defined. While persistent oxidative stress is one of the leading perpetrators of endothelial dysfunction, not all oxidative stress results in vasoconstriction. Free oxygen radicals and related reactants can evoke vasoconstriction as well as vasodilation [43]: e.g. both hydrogen peroxide and hydroxyl radical, stemming from superoxide anion reactions, act as direct vasodilators of vascular smooth muscle and as stimulants of nitric oxide generation from the endothelium. From our results we would have to speculate that in otherwise healthy men the balance of vasoconstrictor and vasodilator substances generated in response to chronic smoking may be tipped towards vasodilation at least in some vascular beds, e.g. in preglomerular arterioles. A resultant lag in preglomerular vasoconstriction in the presence of increasing blood pressure values may characterize an early defect in renal hemodynamic autoregulation in male chronic smokers that has not been described previously. The phenomenon of an increased endothelium-dependent vasodilation in the kidney in the presence of reduced endothelial function in the systemic circulation has recently been described by Cherney et al. in patients with uncomplicated type 1 diabetes mellitus [44].

In our study changes in renal hemodynamics in smoking men did not translate into changes in GFR. This may be due to the small sample size. It would seem feasible that an increased ERPF with higher blood pressure values precedes an increase in GFR. In the long term smoking-induced alterations in renal hemodynamics combined with rising blood pressure could thus result in hyperfiltration and promote loss of renal function. This is where the proposed mechanisms for renal damage associated with chronic smoking meet those of early diabetic nephropathy. In line with this, a number of large cross sectional studies have described an association of chronic smoking with glomerular hyperfiltration [10-13, 45]. Brenner's hyperfiltration theory suggests that elevated glomerular pressure, i.e. glomerular hypertension, induces and maintains nephropathy by adding a hemodynamic burden [46, 47]. As a consequence a vicious circle is established, with an accelerated progression of renal impairment and overt nephropathy $[48,49]$.

Men have consistently been pointed out to be at greater risk of smoking-associated renal function impairment. Findings in women are contradictory $[8,26,50]$. In a populationbased cross-sectional study Briganti et al. showed that smoking increased the risk of renal impairment in men but not in women with an odds ratio of 3.6 [13].

Sex based differences in the incidence and severity of vascular disease are well documented [51]. Emerging evidence suggests that sex-hormone-dependent differences in handling of vascular oxidative stress may play an important role for this phenomenon. Effects of oestrogens and androgens on endothelial function in healthy individuals likely contribute to the development of glomerular sclerosis [52-55]. Oestrogens are supposed to protect the vasculature from oxidant injuries, e.g. induced by smoking, in women [56, 57]. In general, oestrogens are thought to be responsible for the fact that premenopausal women suffer less from arterial hypertension and cardiovascular disease than men or postmenopausal women $[57,58]$. From this it might be expected that menopause would affect associations of smoking 


\section{Kidney \\ Blood Pressure Research}

with altered renal hemodynamics. This was not the case in our cohort, possibly due to the small number of menopausal smoking women.

Interpretation of our findings is limited by several factors: The screening measures for individuals prior to kidney donation were not primarily designed for scientific observation, otherwise a different method for establishing GFR might have been chosen. The retrospective study design, the cross-sectional nature of the data and the relatively small number of subjects additionally demand that any conclusions should be taken with caution.

\section{Conclusion}

Nevertheless, in summary our data suggest that female sex may protect against detrimental effects of smoking on renal autoregulation. The sex-dependent differences were unmasked only when blood pressure levels were taken into account, indicating a putative additive effect of smoking and blood pressure. Of note, in our study this was true even for blood pressure values in the normal range. An increased glomerular hydrostatic pressure as calculated for male smokers may be an important factor promoting a loss of renal function.

\section{Conflict of Interests}

The authors of this manuscript state that they have nothing to disclose.

\section{Abbreviations}

$\mathrm{P}_{\mathrm{G}}=$ Glomerular hydrostatic pressure ( $\mathrm{mmHg}$ ); $\mathrm{K}_{\mathrm{FG}}=$ Filtration coefficient of glomerular capillaries (is known to be $0.154 \pm 0.018(\mathrm{~mL} / \mathrm{sec} / \mathrm{mmHg}$ ); GFR = Glomerular filtration rate $(\mathrm{mL} / \mathrm{min}) ; \mathrm{H}_{\mathrm{T}}=$ Hydrostatic pressure in the Bowman's space (assumed to be $10 \mathrm{mmHg}$ ); $\mathrm{TP}=$ Plasma total protein concentration (g/dL); FF = Filtration fraction (GFR/ERPF); $\mathrm{R}_{\mathrm{A}}=$ Afferent arteriolar resistance; $\mathrm{R}_{\mathrm{E}}=\mathrm{Efferent}$ arteriolar resistance; $\mathrm{ERBF}=$ Renal blood flow rate (ERPF $\mathrm{x}$ $1 / 1$ - Hematocrit) $(\mathrm{mL} / \mathrm{min})$.

\section{Acknowledgemtents}

The publication costs for this paper are payed for by the Deutsche Forschungsgemeinschaft (DFG).

\section{References}

1 Doll R, Peto R, Boreham J, Sutherland I: Mortality in relation to smoking: 50 years' observations on male British doctors. BMJ 2004;328:1519.

2 Bartecchi CE, MacKenzie TD, Schrier RW: The human costs of tobacco use (1). N Engl J Med 1994;330:907912.

3 MacKenzie TD, Bartecchi CE, Schrier RW: The human costs of tobacco use (2). N Engl J Med 1994;330:975980.

-4 Nuyts GD, Van Vlem E, Thys J, De Leersnijder D, D'Haese PC, Elseviers MM, De Broe ME: New occupational risk factors for chronic renal failure. Lancet 1995;346:7-11.

-5 Gall MA, Hougaard P, Borch-Johnsen K, Parving HH: Risk factors for development of incipient and overt diabetic nephropathy in patients with non-insulin dependent diabetes mellitus: prospective, observational study. BMJ 1997;314:783-788. 


\section{Kidney \\ Blood Pressure Research}

Kidney Blood Press Res 2013;37:611-621

\begin{tabular}{l|l}
\hline DOI: $10.1159 / 000355741$ & (c) 2013 S. Karger AG, Basel \\
\hline
\end{tabular}

Published online: December 15, 2013

www.karger.com/kbr

Guberina et al.: Smoking-Induced Changes of Renal Hemodynamics

6 Yacoub R, Habib H, Lahdo A, Al Ali R, Varjabedian L, Atalla G, Kassis Akl N, Aldakheel S, Alahdab S, Albitar S: Association between smoking and chronic kidney disease: a case control study. BMC Public Health 2010;10:731.

7 Stegmayr BG: A study of patients with diabetes mellitus (type 1) and end-stage renal failure: tobacco usage may increase risk of nephropathy and death. J Intern Med 1990;228:121-124.

-8 Orth SR, Stockmann A, Conradt C, Ritz E, Ferro M, Kreusser W, Piccoli G, Rambausek M, Roccatello D, Schafer K, Sieberth HG, Wanner C, Watschinger B, Zucchelli P: Smoking as a risk factor for end-stage renal failure in men with primary renal disease. Kidney Int 1998;54:926-931.

-9 Auerbach O, Carter HW, Garfinkel L, Hammond EC: Cigarette smoking and coronary artery disease. A macroscopic and microscopic study. Chest 1976;70:697-705.

10 Black HR, Zeevi GR, Silten RM, Walker Smith GJ: Effect of heavy cigarette smoking on renal and myocardial arterioles. Nephron 1983;34:173-179.

11 Mimran A, Ribstein J, DuCailar G, Halimi JM: Albuminuria in normals and essential hypertension. J Diabetes Complications 1994;8:150-156.

12 Pinto-Sietsma SJ, Mulder J, Janssen WM, Hillege HL, de Zeeuw D, de Jong PE: Smoking is related to albuminuria and abnormal renal function in nondiabetic persons. Ann Intern Med 2000;133:585-591.

13 Briganti EM, Branley P, Chadban SJ, Shaw JE, McNeil JJ, Welborn TA, Atkins RC: Smoking is associated with renal impairment and proteinuria in the normal population: the AusDiab kidney study. Australian Diabetes, Obesity and Lifestyle Study. Am J Kidney Dis 2002;40:704-712.

14 Gambaro G, Verlato F, Budakovic A, Casara D, Saladini G, Del Prete D, Bertaglia G, Masiero M, Checchetto S, Baggio B: Renal impairment in chronic cigarette smokers. J Am Soc Nephrol 1998;9:562-567.

15 Green MS, Jucha E, Luz Y: Blood pressure in smokers and nonsmokers: epidemiologic findings. Am Heart J 1986;111:932-940.

-16 Fesler P, du Cailar G, Ribstein J, Mimran A: Heterogeneity of cardiorenal characteristics in normotensive subjects. Hypertension 2004;43:219-223.

17 Loutzenhiser R, Bidani A, Chilton L: Renal myogenic response: kinetic attributes and physiological role. Circ Res 2002;90:1316-1324.

18 Ljungman S, Aurell M, Hartford M, Wikstrand J, Wilhelmsen L, Berglund G: Blood pressure and renal function. Acta Med Scand 1980;208:17-25.

19 Halimi JM, Philippon C, Mimran A: Contrasting renal effects of nicotine in smokers and non-smokers. Nephrol Dial Transplant 1998;13:940-944.

-20 Ritz E, Benck U, Franek E, Keller C, Seyfarth M, Clorius J: Effects of smoking on renal hemodynamics in healthy volunteers and in patients with glomerular disease. J Am Soc Nephrol 1998;9:1798-1804.

-21 Orth SR, Ritz E, Schrier RW: The renal risks of smoking. Kidney Int 1997;51:1669-1677.

22 Neugarten J, Acharya A, Silbiger SR: Effect of gender on the progression of nondiabetic renal disease: a meta-analysis. J Am Soc Nephrol 2000;11:319-329.

23 Erdely A, Greenfeld Z, Wagner L, Baylis C: Sexual dimorphism in the aging kidney: Effects on injury and nitric oxide system. Kidney Int 2003;63:1021-1026.

24 Abecassis M, Adams M, Adams P, Arnold RM, Atkins CR, Barr ML, Bennett WM, Bia M, Briscoe DM, Burdick J, Corry RJ, Davis J, Delmonico FL, Gaston RS, Harmon W, Jacobs CL, Kahn J, Leichtman A, Miller C, Moss D, Newmann JM, Rosen LS, Siminoff L, Spital A, Starnes VA, Thomas C, Tyler LS, Williams L, Wright FH, Youngner S: Consensus statement on the live organ donor. JAMA 2000;284:2919-2926.

25 WHO/Europe: "European Health for All Database (HFA-DB)"

-26 Ejerblad E, Fored CM, Lindblad P, Fryzek J, Dickman PW, Elinder CG, McLaughlin JK, Nyren O: Association between smoking and chronic renal failure in a nationwide population-based case-control study. J Am Soc Nephrol 2004;15:2178-2185.

-27 Jafri RA, Britton KE, Nimmon CC, Solanki K, Al-Nahhas A, Bomanji J, Fettich J, Hawkins LA: Technetium-99m MAG3, a comparison with iodine-123 and iodine-131 orthoiodohippurate, in patients with renal disorders. J Nucl Med 1988;29:147-158.

28 Fesler P, du Cailar G, Ribstein J, Mimran A: Glomerular hemodynamics and arterial function in normal individuals. J Hypertens 2010;28:2462-2467.

-29 Smilde TD, Damman K, van der Harst P, Navis G, Westenbrink BD, Voors AA, Boomsma F, van Veldhuisen DJ, Hillege HL: Differential associations between renal function and "modifiable" risk factors in patients with chronic heart failure. Clin Res Cardiol 2009;98:121-129.

-30 Gomez DM: Evaluation of renal resistances, with special reference to changes in essential hypertension. J Clin Invest 1951;30:1143-1155. 


\section{Kidney \\ Blood Pressure Research}

Guberina et al.: Smoking-Induced Changes of Renal Hemodynamics

-31 Kimura G, London GM, Safar ME, Kuramochi M, Omae T: Glomerular hypertension in renovascular hypertensive patients. Kidney Int 1991;39:966-972.

-32 Kayler LK, Meier-Kriesche HU, Punch JD, Campbell DA, Jr., Leichtman AB, Magee JC, Rudich SM, Arenas JD, Merion RM: Gender imbalance in living donor renal transplantation. Transplantation 2002;73:248-252.

33 Wesson LG: Renal hemodynamics in physiological states; In: The physiology of the humand kidney. New York, Grune \& Stratton, 1969, pp. 96-106.

34 Bjornsson TD: Use of serum creatinine concentrations to determine renal function. Clin Pharmacokinet 1979;4:200-222.

35 Slack TK, Wilson DM: Normal renal function: CIN and CPAH in healthy donors before and after nephrectomy. Mayo Clin Proc 1976;51:296-300.

-36 Loutzenhiser R, Bidani AK, Wang X: Systolic pressure and the myogenic response of the renal afferent arteriole. Acta Physiol Scand 2004;181:407-413.

-37 Halmai R, Szijarto IA, Feher E, Fesus G, Molnar GA, Brasnyo P, Fulop F, Gollasch M, Koller A, Wittmann I: Cigarette smoke elicits relaxation of renal arteries. Eur J Clin Invest 2011;41:195-202.

-38 Michael Pittilo R: Cigarette smoking, endothelial injury and cardiovascular disease. Int J Exp Pathol 2000;81:219-230.

-39 Barua RS, Ambrose JA, Eales-Reynolds LJ, DeVoe MC, Zervas JG, Saha DC: Dysfunctional endothelial nitric oxide biosynthesis in healthy smokers with impaired endothelium-dependent vasodilatation. Circulation 2001;104:1905-1910.

40 Toda N, Toda H: Nitric oxide-mediated blood flow regulation as affected by smoking and nicotine. Eur J Pharmacol 2010;649:1-13.

41 Rahman MM, Laher I: Structural and functional alteration of blood vessels caused by cigarette smoking: an overview of molecular mechanisms. Curr Vasc Pharmacol 2007;5:276-292.

42 Armani C, Landini L, Jr., Leone A: Molecular and biochemical changes of the cardiovascular system due to smoking exposure. Curr Pharm Des 2009;15:1038-1053.

43 Rubanyi GM: Vascular effects of oxygen-derived free radicals. Free Radic Biol Med 1988;4:107-120.

44 Cherney DZ, Reich HN, Jiang S, Har R, Nasrallah R, Hebert RL, Lai V, Scholey JW, Sochett EB: Hyperfiltration and effect of nitric oxide inhibition on renal and endothelial function in humans with uncomplicated type 1 diabetes mellitus. Am J Physiol Regul Integr Comp Physiol 2012;303:R710-718.

45 Maeda I, Hayashi T, Sato KK, Koh H, Harita N, Nakamura Y, Endo G, Kambe H, Fukuda K: Cigarette smoking and the association with glomerular hyperfiltration and proteinuria in healthy middle-aged men. Clin J Am Soc Nephrol 2011;6:2462-2469.

46 Brenner BM, Lawler EV, Mackenzie HS: The hyperfiltration theory: a paradigm shift in nephrology. Kidney Int 1996;49:1774-1777.

47 Anderson S, Brenner BM: Effects of aging on the renal glomerulus. Am J Med 1986;80:435-442.

48 Remuzzi G: Cigarette smoking and renal function impairment. Am J Kidney Dis 1999;33:807-813.

49 Orth SR, Ogata H, Ritz E: Smoking and the kidney. Nephrol Dial Transplant 2000;15:1509-1511.

50 Stengel B, Couchoud C, Cenee S, Hemon D: Age, blood pressure and smoking effects on chronic renal failure in primary glomerular nephropathies. Kidney Int 2000;57:2519-2526.

-51 Vassalle C, Novembrino C, Maffei S, Sciarrino R, De Giuseppe R, Vigna L, de Liso F, Mercuri A, Bamonti F: Determinants of oxidative stress related to gender: relevance of age and smoking habit. Clin Chem Lab Med 2011;49:1509-1513.

52 Forte P, Kneale BJ, Milne E, Chowienczyk PJ, Johnston A, Benjamin N, Ritter JM: Evidence for a difference in nitric oxide biosynthesis between healthy women and men. Hypertension 1998;32:730-734.

53 Orshal JM, Khalil RA: Gender, sex hormones, and vascular tone. Am J Physiol Regul Integr Comp Physiol 2004;286:R233-249.

54 Reckelhoff JF: Gender differences in the regulation of blood pressure. Hypertension 2001;37:1199-1208.

55 Kwan G, Neugarten J, Sherman M, Ding Q, Fotadar U, Lei J, Silbiger S: Effects of sex hormones on mesangial cell proliferation and collagen synthesis. Kidney Int 1996;50:1173-1179.

-56 Hellstrom HR: Mechanism of protection against vascular smoking-induced changes by hormone replacement therapy. J Am Coll Cardiol 2000;35:815-816.

57 Miller AA, De Silva TM, Jackman KA, Sobey CG: Effect of gender and sex hormones on vascular oxidative stress. Clin Exp Pharmacol Physiol 2007;34:1037-1043.

-58 Witteman JC, Grobbee DE, Kok FJ, Hofman A, Valkenburg HA: Increased risk of atherosclerosis in women after the menopause. BMJ 1989;298:642-644. 